\title{
AN ATTEMPT TO COMPARE THE FITNESS OF POLY- MORPHIC AND MONOMORPHIC EXPERIMENTAL POPULATIONS OF DROSOPHILA PSEUDOOBSCURA
}

\author{
J. A. BEARDMORE,* TH. DOBZHANSKY, $\dagger$ and O. A. PAVLOVSKY $\dagger$ \\ Department of Zoology, Columbia University, New York
}

\section{INTRODUCTION}

Received I8.ii.59

Ghromosomal polymorphism, due to inversions of blocks of genes, is widespread in natural populations of many species of Drosophila. The polymorphism is probably almost always adaptive and usually balanced. Experimental populations which contain mixtures of karyotypes as a rule reach stable equilibria; this indicates that the structural heterozygotes are heterotic. The adaptive values of the karyotypes are, however, quite sensitive to environmental variations; the superior fitness of the heterozygotes may be more pronounced in some environments than in others, and it may even be absent altogether. It appears, however, that the heterozygotes possess net adaptive advantages over the range of the environments to which the population is exposed in its natural habitats.

Direct comparisons of the fitnesses of polymorphic and monomorphic populations have, however, seldom been attempted. This is the problem to which we address ourselves in the pages that follow. Third chromosomes with $\mathrm{AR}$ and with $\mathrm{CH}$ gene arrangements are common in many populations of Drosophila pseudoobscura in California and elsewhere. Dobzhansky (I948, I957), Levine (I 955), and Levene, Pavlovsky, and Dobzhansky (1958) have shown that experimental populations which contain these chromosomes are subject to strong selection which at $25^{\circ} \mathrm{C}$. conduces to an equilibrium of about $70-75$ percent $\mathrm{AR}$ and 25-30 percent $\mathrm{CH}$. Taking the fitness of $\mathrm{AR} / \mathrm{CH}$ heterozygotes to be unity, that of $\mathrm{AR} / \mathrm{AR}$ homozygotes turns out to lie, in different experiments, between 0.65 and 0.85 , and that of $\mathrm{CH} / \mathrm{CH}$ homozygotes between $0 \cdot 42$ and $0 \cdot 60$. We have accordingly set up several experimental populations with $\mathrm{AR}$ and $\mathrm{CH}$ chromosomes in laboratory population cages. Three of these were polymorphic populations containing $\mathrm{AR}$ and $\mathrm{CH}$ chromosomes, two monomorphic populations with only $A R$, and two monomorphic populations with $\mathrm{CH}$ chromosomes. After several generations during which the populations might have undergone selection for adaptation to the environments of the population cages, attempts were made to obtain estimates of certain parameters which we believe to be significant for evaluation of the fitness of the populations.

\footnotetext{
* Commonwealth Fund Fellow; present address, Department of Genetics, The University, Sheffield, England.

$\dagger$ The work under Contract No. AT-(30-I)- i I 51, U.S. Atomic Energy Commission.
} 


\section{MATERIAL AND TECHNIQUES}

The foundation stocks of the experimental populations were prepared using I 6 strains homozygous for AR, and 13 strains homozygous for $\mathrm{CH}$, all derived from flies collected in the locality of Pinon Flats, Mount San Jacinto, in California. The foundation stocks of the monomorphic AR and $\mathrm{CH}$ populations consisted of about 2000 flies each, obtained by intercrossing about equal numbers of flies from all the AR or $\mathrm{CH}$ strains respectively. The polymorphic populations were also descended from 2000 founders each, but were obtained by intercrosses of all the available $\mathrm{AR}$ and $\mathrm{CH}$ strains; the foundation stocks were so contrived that the initial gametic frequencies of $\mathrm{AR}$ and $\mathrm{CH}$ chromosomes were 0.2 and 0.8 respectively. The experimental populations were started on the following dates (all in 1957) :

$\begin{array}{ccl}\text { Population no. } & \text { Chromosomes } & \text { Date } \\ \text { I } 73 & \text { AR }+ \text { CH } & \text { January Io } \\ \text { I } 74 & \text { GH } & \text { January I I } \\ \text { I } 75 & \text { AR } & \text { February I } \\ \text { I76 } & \text { AR }+ \text { CH } & \text { February 5 } \\ \text { I80 } & \text { AR } & \text { May I I } \\ \text { I8I } & \text { AR }+ \text { CH } & \text { May I I } \\ \text { I82 } & \text { CH } & \text { May I I }\end{array}$

All the populations wcre kept in wooden cages containing 15 food cups each, a fresh cup being inserted generally on alternate days. Nos. I $74^{-1} 82$ were kept at $25^{\circ} \mathrm{C}$. in well-regulated incubators provided with electric fans, and No. 173 at $25^{\circ}$ but in a constant temperature room with poor ventilation. From time to time a cup with food in which pupæ were beginning to form was withdrawn from each of a series of cages (Nos. I 73-1 76 or Nos. $180-182$ ), attached by adhesive tape to a glass "chimney" having a diameter equal to that of the cup, provided with a cotton stopper and placed in an incubator at $25^{\circ} \mathrm{C}$. When the adults began hatching in the cups, they were collected daily (including Sundays), etherised, counted, and weighed individually on a Misco Quartz Helix Balance, on which a load of $5 \mathrm{mg}$. caused an extension of $67 \mathrm{~mm}$. from zero (read to one-half of a $\mathrm{mm}$.). Only flies with fully expanded and hardened wings were weighed. It is important for the evaluation of the data in tables 2-6 to note that the samples from the different cages werc not taken simultaneously. The series of populations Nos. I 73-1 76 were sampled between 5 th November 1957 and 9th January 1958, and again between 8 th and I6th June 1958. The series of populations Nos. I80-182 were sampled between 3 oth January and 30 th May, and again between 27 th June and 15 th July 1958. It will be seen that during most of $195^{8}$ the populations were in better condition than during 1957 , as a consequence of which the cups yielded more flies in 1958 than in 1957.

The two scrics of populations are, thus, not necessarily comparable, while the populations within a series are, with the possible exception of No. I 73 (see above).

At approximately the same time as each cup to be used for the determination of the biomass was taken from each of the populations, another similar cup was removed for the purpose of mcasuring wing length. All the flies were allowed to emerge from such a cup and a random sample taken from the total emergence in each cup. Ten samples (cups) were taken from each of populations 173,176, I 75 and 177 and five samples from populations $180-2$. The number per sample was fifty flies of each sex, or the total emergence if this was less than fifty flies; no fly was rcjected for any reason other than torn or crumpled wings. Both wings were then removed from each fly and mounted in paraffin oil under cover-glasses, ten pairs of wings to a slide, with the left wings forming a lower row and the right wings an upper row. The measurement of wing length was accomplished using a wideficld binocular microscope at a magnification of $60 \times$, with a standard eyepiece micrometer, divided into Ioo divisions; wing lengths were estimated to 
one-tenth of a scale division. The distance chosen to represent wing length was from a point near the posterior end of the humeral cross-vein to the tip of the wing near the end of the third vein, such distance in an average wing corresponding to about 85 units of the micrometer scale.

\section{RESULTS}

(i) The selection process in the polymorphic populations

The changes which took place in the three polymorphic populations are shown in table $\mathrm{I}$. The foundation stocks had 20 percent of AR and $8 \mathrm{o}$ percent of $\mathrm{CH}$ chromosomes. Control samples taken in two populations fourteen days after the start (i.e., eggs from the surviving individuals of the foundation stocks) had, as expected, the initial

TABLE I

Changes in the frequencies of $A R$ and $C H$ chromosomes in the polymorphic populations (in percent)

\begin{tabular}{|c|c|c|c|c|c|c|}
\hline \multirow{2}{*}{ Days } & \multicolumn{2}{|c|}{173} & \multicolumn{2}{|c|}{176} & \multicolumn{2}{|c|}{ I $8 \mathrm{I}$} \\
\hline & AR & $\mathrm{CH}$ & $\mathrm{AR}$ & $\mathrm{CH}$ & AR & $\mathrm{CH}$ \\
\hline 0 & $20 \cdot 0$ & $80 \cdot 0$ & $20 \cdot 0$ & $80 \cdot 0$ & $20 \cdot 0$ & $80 \cdot 0$ \\
\hline 14 & $22 \cdot 7$ & $77 \cdot 3$ & $20 \cdot 7$ & $79 \cdot 3$ & $\ldots$ & $\ldots$ \\
\hline 35 & $39 \cdot 3$ & $60 \cdot 7$ & $40 \cdot 0$ & $60 \cdot 0$ & $40 \cdot 7$ & $59 \cdot 3$ \\
\hline 70 & $45^{\circ} \mathrm{O}$ & $55^{\circ}$ & $48 \cdot 3$ & $5 I \cdot 7$ & $4 \mathrm{I} \cdot 3$ & $58 \cdot 7$ \\
\hline 105 & $50 \cdot 0$ & $50 \cdot 0$ & $50 \cdot 3$ & $49 \cdot 7$ & $55 \cdot 3$ & $44 \cdot 7$ \\
\hline 140 & $60 \cdot 7$ & $39 \cdot 3$ & $56 \cdot 7$ & $43 \cdot 4$ & & \\
\hline 175 & $57 \cdot 3$ & $42 \cdot 7$ & & $\ldots$ & & $\ldots$ \\
\hline $264-275$ & $66 \cdot 3$ & $33 \cdot 7$ & $66 \cdot 3$ & $33 \cdot 7$ & $67 \cdot 7$ & $32 \cdot 3$ \\
\hline 302 & $64 \cdot 3$ & 35.7 & $\ldots$ & & & \\
\hline 365 & $64 \cdot 3$ & $35 \cdot 7$ & $71 \cdot 3$ & $28 \cdot 7$ & $67 \cdot 7$ & $3^{2} \cdot 3$ \\
\hline 488 & $\cdots$ & $\ldots$ & $78 \cdot 3$ & $\cdots$ & $69^{\circ} 0$ & $3 I \cdot 0$ \\
\hline $\begin{array}{l}503 \\
6 \text { ro }\end{array}$ & $72 \cdot 7$ & $27 \cdot 3$ & $\ldots$ & $\begin{array}{c}21.7 \\
\ldots\end{array}$ & $\ldots$ & $\ldots$ \\
\hline
\end{tabular}

frequencies unchanged. In the first generation developing in the cages, the frequency of AR chromosomes about doubled (see the 35th day sample in table I; the mean generation length in these populations is estimated to be about 25 days). In about four generations from the start, the $\mathrm{AR}$ and $\mathrm{CH}$ chromosomes became equally frequent (the 105th day samples). A year after the start an equilibrium was approached but apparently not yet fully attained. The samples in which the flies were counted, weighed, and measured were, thus, taken during the period in the life of the polymorphic populations when the latter consisted of about $45^{-5} 5^{\circ}$ percent of $\mathrm{AR} / \mathrm{CH}$ structural heterozygotes, and when the incidence of AR homozygotes was greater than that of $\mathrm{CH}$ homozygotes.

\section{(ii) Number of flies produced}

The means and variances of the numbers of the flies which hatched from the cups taken from the different population cages are reported 
in table 2. The amounts of the food medium placed in the different cups were, of course, as uniform as practicable (about $25 \mathrm{cc}$.). The number of the eggs which the flies in the population cages deposit on each cup is probably always greater, and frequently greater by at least one order of magnitude, than the number of adult flies which eventually hatches. The number of the adults that hatch is, thus, an indication of the ability of the genotypes in a given population to utilise successfully the environmental opportunities at their disposal.

It can be seen at a glance that the first series of populations (Nos. I 73-I77) was less productive than the second series (Nos. I 80-182). As stated above, this is ascribable to environmental conditions during the year $195^{8}$ being better than during 1957. What interests us are

TABLE 2

Number of flies hatching per cup in different populations

\begin{tabular}{|c|c|c|c|c|c|}
\hline Population & Sex & Mean & Variance & $\begin{array}{l}\text { Variation } \\
\text { coefficient }\end{array}$ & $\begin{array}{c}\text { Cups } \\
\text { examined }\end{array}$ \\
\hline${ }_{173}, \mathrm{AR}+\mathrm{CH}$ & Female & $99 \cdot 93$ & 1629 & $40 \cdot 4$ & 33 \\
\hline $176, \mathrm{AR}+\mathrm{CH}$ & Female & $131 \cdot 50$ & 2265 & $3^{6} \cdot 2$ & 33 \\
\hline $175, \mathrm{AR}$ & Female & $86 \cdot 24$ & 1985 & $5 \sqrt{1 \cdot 7}$ & 33 \\
\hline $177, \mathrm{CH}$ & Female & $97 \cdot 88$ & $278 \mathrm{r}$ & 53.9 & 33 \\
\hline $\mathrm{I} 8 \mathrm{I}, \mathrm{AR}+\mathrm{CH}$ & Female & I88.35 & $33^{8} 3$ & 30.8 & 20 \\
\hline $180, A R$ & Female & 1 39.75 & $4^{218}$ & $4^{6 \cdot 4}$ & 20 \\
\hline $182, \mathrm{CH}$ & Female & 119.80 & 2487 & $4 \mathrm{r} \cdot \hat{6}$ & 20 \\
\hline $173, \mathrm{AR}+\mathrm{CH}$ & Male & $70 \cdot 27$ & 877 & $40^{2} \cdot 1$ & 33 \\
\hline I $76, \mathrm{AR}+\mathrm{CH}$ & Male & 85.27 & 1072 & $38 \cdot 4$ & 33 \\
\hline $175, \mathrm{AR}$ & Male & $60 \cdot 82$ & 806 & $46 \cdot 7$ & 33 \\
\hline $177, \mathrm{CH}$ & Male & 65.09 & 1284 & $55^{\circ} \mathrm{I}$ & 33 \\
\hline $181, \mathrm{AR}+\mathrm{CH}$ & Male & 138.90 & 2523 & $36 \cdot 2$ & 20 \\
\hline $180, \mathrm{AR}$ & Male & $90 \cdot 65$ & 2082 & $50 \cdot 4$ & 20 \\
\hline $182, \mathrm{CH}$ & Male & $82 \cdot 45$ & 1736 & $5^{0} \cdot 5$ & 20 \\
\hline
\end{tabular}

comparisons of the polymorphic and monomorphic populations sampled simultaneously. The polymorphic populations Nos. 173 and 176 produced respectively $99^{\circ} 9 \pm 7 \cdot \mathrm{I}$ and $\mathrm{I} 3 \mathrm{I}^{\circ} \cdot 5 \pm 8 \cdot 4$ females and $70 \cdot 3 \pm 5^{\cdot 2}$ and $85 \cdot 3 \pm 5 \cdot 8$ males per cup. The differences between Nos. I 73 and I 76 are again ascribable to the environment (see above). The monomorphic populations, Nos. I 75 and 177 , yielded respectively $86 \cdot 2 \pm 7 \cdot 9$ and $97 \cdot 9 \pm 9 \cdot 3$ females and $60 \cdot 8 \pm 5 \cdot 0$ and $65 \cdot 1 \pm 6 \cdot 3$ males. The productivity of the monomorphic populations is thus not significantly lower than No. I 76, both for females and for males. Since the populations Nos. 1 75, 176, I 77 were kept in identical environments, they are fully comparable, while No. I 73 is not quite so.

In the second series, the polymorphic population No. I8 I produced I $88 \cdot 3 \pm \mathrm{I} 3 \cdot 3$ females and $\mathrm{I} 38 \cdot 9 \pm \mathrm{II} \cdot 5$ males per cup. The monomorphic populations Nos. I 80 and 182 yielded only $139.8 \pm \mathbf{I} 4.9$ and I $9 \cdot 8 \pm \mathrm{II} \cdot 4$ females and $90 \cdot 7 \pm 10 \cdot 5$ and $82 \cdot 5 \pm 9 \cdot 6$ males per cup. The productivity of the polymorphic population is again significantly greater. 
Table 2 also shows the variances and the coefficients of variation of the productivity in the different populations. The productivity of the polymorphic populations is consistently less variable than that of the monomorphic ones. The six variation coefficients for the polymorphic populations range from $30 \cdot 8$ to $42 \cdot \mathrm{I}$, and for the monomorphic ones from $4 \mathrm{I} \cdot 6$ to $53 \cdot 9$. The first series of populations

TABLE 3

Weight (in mg.) of fies in polymorphic populations

\begin{tabular}{|c|c|c|c|c|c|c|c|c|}
\hline \multicolumn{3}{|c|}{ No. 173} & \multicolumn{3}{|c|}{ No. 176} & \multicolumn{3}{|c|}{ No. I8I } \\
\hline Mean & $s^{2}$ & Flies & Mean & $s^{2}$ & Flies & Mean & $s^{2}$ & Flies \\
\hline \multicolumn{3}{|c|}{ Females } & \multicolumn{3}{|c|}{ Females } & \multicolumn{3}{|c|}{ Females } \\
\hline 0.804 & 0.0120 & 80 & 0.889 & $0.029 \mathrm{I}$ & I 10 & 0.912 & 0.0140 & I 27 \\
\hline 0.897 & 0.0234 & 65 & 0.845 & 0.0206 & 160 & 0.786 & 0.0223 & 164 \\
\hline $0 \cdot 783$ & 0.0116 & 83 & o.949 & O.0I 53 & 117 & 0.737 & 0.0150 & 143 \\
\hline $0.73^{8}$ & 0.0112 & 96 & 0.910 & o.0I33 & II 5 & 0.873 & O.0153 & 132 \\
\hline 0.845 & 0.0177 & 100 & 0.659 & $0.016 \mathrm{I}$ & 134 & 0.816 & 0.0228 & 247 \\
\hline 0.929 & o.0199 & 91 & 0.776 & 0.0209 & 143 & 0.730 & 0.0354 & 261 \\
\hline 0.975 & 0.0298 & 93 & 0.754 & $0.029 \mathrm{I}$ & 87 & 0.678 & 0.0218 & 265 \\
\hline I. 026 & o.0133 & 99 & 0.752 & 0.0158 & 148 & 0.691 & 0.0293 & 204 \\
\hline $0 \cdot 765$ & 0.0309 & 215 & 0.688 & 0.0247 & 226 & $\mathrm{I} \cdot \mathrm{I} 08$ & 0.0245 & 162 \\
\hline 0.727 & 0.0201 & 140 & $0.74 \mathrm{I}$ & 0.0300 & 150 & $\mathrm{I} \cdot 037$ & 0.0148 & 125 \\
\hline \multicolumn{3}{|c|}{ Males } & \multicolumn{3}{|c|}{ Males } & \multicolumn{3}{|c|}{ Males } \\
\hline $0.72 \mathrm{I}$ & 0.0108 & 39 & $0 \cdot 769$ & o.0II9 & 53 & 0.803 & 0.0138 & 59 \\
\hline $0 \cdot 796$ & $0.013 \mathrm{I}$ & 45 & 0.729 & o.0o99 & 90 & 0.665 & $0.02 \mathrm{II}$ & I 24 \\
\hline 0.686 & $0.008_{4}$ & 34 & 0.789 & O०OIOI & 77 & 0.660 & 0.0145 & $9^{2}$ \\
\hline 0.636 & 0.0104 & 79 & 0.770 & o.0054 & $4 \mathrm{I}$ & 0.762 & $0 \cdot 0096$ & 70 \\
\hline 0.679 & 0.0148 & 70 & 0.601 & 0.0100 & 69 & 0.709 & 0.0157 & I 45 \\
\hline 0.846 & 0.0103 & 59 & 0.700 & 0.0117 & I I I & 0.635 & 0.0253 & 217 \\
\hline 0.803 & 0.0145 & 68 & 0.696 & $0.015^{\circ}$ & 57 & 0.656 & o.0159 & 197 \\
\hline $0.86 \overline{6}$ & 0.0069 & 55 & 0.687 & 0.0140 & 84 & 0.633 & $0.014^{2}$ & I 57 \\
\hline 0.674 & $0 \cdot 0206$ & I 39 & 0.604 & о.0138 & 169 & $\mathrm{I} \cdot 04 \mathrm{I}$ & 0.0165 & 124 \\
\hline $0.66^{2}$ & 0.0120 & II 5 & 0.673 & $0.014 \mathrm{I}$ & 145 & $0.89^{2}$ & 0.0137 & 84 \\
\hline
\end{tabular}

seems to be more variable than the second, but the difference is not significant.

Note should be taken of the deviation from the normal ratio of sexes observed regularly in all populations. The male sex is deficient, forming only 39 per cent. to $4 \mathrm{I}$ per cent. of the total. Such a scarcity of males is usual in overpopulated cultures, the male being obviously the weaker sex.

\section{(iii) Weight of the flies}

The mean weights of the female and male flies in the different populations are reported in tables 3 and 4 . For each population all the flies hatching in each of ten cups were weighed individually, as stated above in the section on Material and Techniques. The 
number of flies in each cup, the mean weights, and the variances of the individual weights $\left(s^{2}\right)$ are given. The data are further summarised in table 5, which shows the unweighted averages of the mean weights of the flies from each of the ten cups in each population. Table 5 shows also the variance of the individual weights of the flies and the variances of the mean weights in the different cups. The variances of " individuals" are unweighted means of the variances reported in

TABLE 4

Weight (in mg.) of flies in monomorphic populations

\begin{tabular}{|c|c|c|c|c|c|c|c|c|c|c|c|}
\hline \multicolumn{3}{|c|}{ No. I 75-AR } & \multicolumn{3}{|c|}{ No. I $77-\mathrm{CH}$} & \multicolumn{3}{|c|}{ No. $180-A R$} & \multicolumn{3}{|c|}{ No. $182-\mathrm{CH}$} \\
\hline Mean & $s^{2}$ & Flies & Mean & $s^{2}$ & Flies & Mean & $s^{2}$ & Flies & Mean & $s^{2}$ & Flies \\
\hline \multicolumn{3}{|c|}{ Females } & \multicolumn{3}{|c|}{ Females } & \multicolumn{3}{|c|}{ Females } & \multicolumn{3}{|c|}{ Females } \\
\hline 0.786 & 0.0571 & I4I & 0.894 & 0.0222 & 70 & 0.932 & 0.0331 & 98 & 0.837 & 0.0269 & I 50 \\
\hline 0.940 & 0.0325 & I4 I & 0.669 & 0.0176 & I 33 & 0.915 & 0.0292 & $8 \mathrm{r}$ & 0.875 & 0.0315 & 100 \\
\hline 0.808 & 0.0278 & 53 & 0.786 & 0.0176 & $7 \mathrm{I}$ & $I \cdot 047$ & 0.0312 & $5^{8}$ & 0.719 & 0.0248 & I 74 \\
\hline 0.954 & 0.0382 & 59 & 0.892 & $0.017 \mathrm{I}$ & 76 & 0.858 & 0.0218 & 47 & 0.762 & 0.0161 & II I \\
\hline 0.760 & 0.0332 & 99 & $0.84^{8}$ & 0.0334 & I I9 & 0.706 & 0.0173 & 180 & 0.564 & 0.0175 & I 34 \\
\hline 0.962 & 0.0324 & 36 & 0.852 & $0.026 \mathrm{I}$ & 103 & $0 \cdot 773$ & 0.0330 & 258 & 0.806 & 0.0282 & I5O \\
\hline 0.762 & 0.0279 & 57 & 0.729 & 0.0422 & 64 & 0.754 & $0.027 \mathrm{I}$ & 276 & 0.874 & 0.0184 & 150 \\
\hline 0.892 & 0.0319 & I I 9 & I.023 & 0.0317 & $9 \mathrm{I}$ & 0.925 & $0 \cdot 0489$ & I 76 & $\mathrm{I} \cdot 03^{2}$ & 0.0419 & 45 \\
\hline 0.680 & 0.0348 & I 34 & 0.726 & 0.0262 & 213 & 1060 & 0.0240 & 84 & I. 072 & 0.0124 & 54 \\
\hline $0.74^{2}$ & 0.0155 & 187 & 0.653 & 0.0207 & $33^{\mathrm{I}}$ & $I \cdot 07 I$ & 0.0125 & 116 & $1 \cdot 085$ & 0.0222 & $4^{2}$ \\
\hline \multicolumn{3}{|c|}{ Males } & \multicolumn{3}{|c|}{ Males } & \multicolumn{3}{|c|}{ Males } & \multicolumn{3}{|c|}{ Males } \\
\hline $0 \cdot 682$ & 0.0317 & IO4 & 0.720 & 0.0169 & 53 & $0.76 \mathrm{I}$ & $0 \cdot 0196$ & 53 & 0.728 & 0.0175 & $\times 28$ \\
\hline $0 \cdot 760$ & 0.0207 & 86 & 0.618 & 0.0142 & 78 & 0.876 & 0.0243 & 57 & 0.699 & 0.0235 & $8 I$ \\
\hline $0.64 \mathrm{I}$ & 0.0175 & 35 & $0 \cdot 73^{8}$ & $0.015^{2}$ & 49 & 0.912 & 0.0119 & 36 & 0.634 & 0.0157 & $9 \mathrm{I}$ \\
\hline 0.773 & 0.0146 & 34 & 0.750 & 0.0150 & 30 & $0.75^{6}$ & $0.014 \mathrm{I}$ & 30 & $\begin{array}{l}0.649 \\
\end{array}$ & $0.008 \mathrm{I}$ & 60 \\
\hline 0.696 & 0.0192 & 83 & 0.746 & 0.0122 & $7 \mathrm{I}$ & 0.703 & 0.0208 & 184 & 0.674 & 0.0192 & 96 \\
\hline 0.762 & 0.0154 & 24 & 0.759 & $0.017 \mathrm{I}$ & 79 & $0.64 \mathrm{I}$ & 0.0154 & 97 & 0.533 & 0.0063 & 85 \\
\hline 0.724 & 0.0160 & 36 & 0.634 & 0.0197 & 44 & 0.665 & $0.014^{2}$ & 181 & 0.768 & 0.0124 & $8_{3}$ \\
\hline 0.779 & 0.0153 & 66 & 0.905 & 0.0237 & $\begin{array}{l}84 \\
87\end{array}$ & 0.826 & 0.0302 & II 2 & 0.8 I I & 0.0218 & 15 \\
\hline $0.58 \mathrm{I}$ & 0.0178 & 90 & $0.6 \mathrm{II}$ & 0.0144 & I 36 & 0.904 & 0.0168 & 65 & 0.890 & 0.0106 & 33 \\
\hline 0.650 & 0.0136 & 145 & $0^{\circ} 55^{\mathrm{I}}$ & 0.0144 & 212 & 0.889 & 0.0126 & 49 & $0.9^{19}$ & 0.0132 & 27 \\
\hline
\end{tabular}

tables 3 and 4 ; these are, then, the average variances of the individual fly weights emerging in the same cup. The variances of "means" are computed from the ten average weights shown, for each population and sex, in tables 3 and 4 ; these variances characterise the reactions of the flies to the differences in the environmental conditions found in the different cups.

Flies from the polymorphic populations are neither consistently heavier nor lighter than those from the monomorphic ones. Examination of the tables and of fig. I shows, however, that there exists, as expected, a rather weak but significant negative correlation between the numbers of the flies emerging per cup and their weights. This only 
means that when fewer flies develop in a given amount of food they are bigger flies. The heterosis in polymorphic populations does not make the flies large. Average weights of female flies exceeding I mg. have been observed only among samples taken during spring and summer of 1958, both in monomorphic and in polymorphic populations. Examination of fig. I suggests, however, that, with equal population

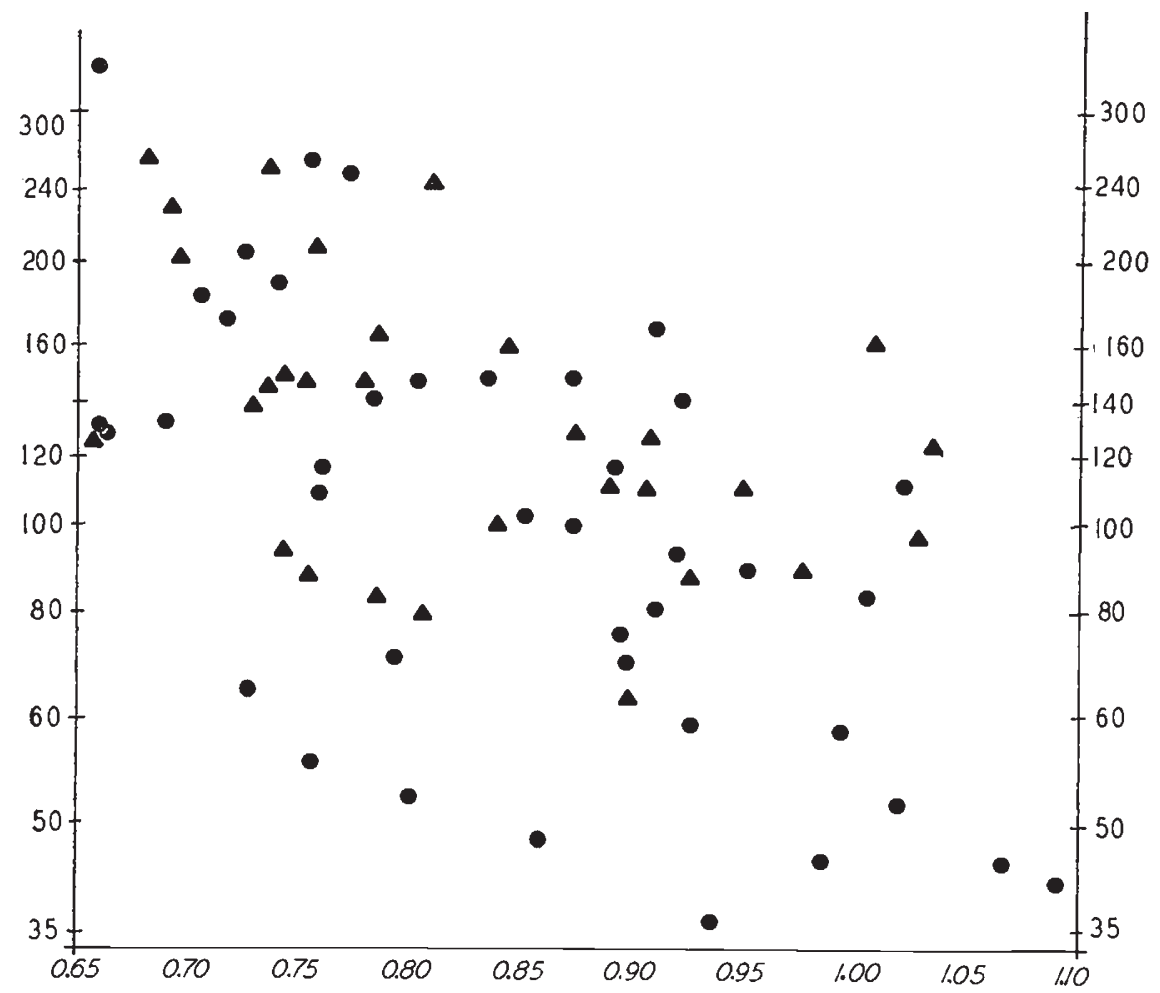

Fig. I.-Mean weight (in mg.) of a female (abscissæ) plotted against the log. of the number of flies hatching in a cup (ordinates).

Circles-monomorphic populations. Triangles-polymorphic populations.

densities, the flies tend to be slightly heavier in polymorphic than in monomorphic populations.

The data on the variability of the body weight are more informative. Table 5 reports the variances of the weights of individuals emerging from the same food cup; consider these data separately for the two sexes and for the two series of the experimental populations (Nos. 173-177 and Nos. I80-182). With the sole exception of males in population 182 , the polymorphic populations show smaller variances than the comparable monomorphic ones. To eliminate the possible disturbing effects of the differences in the average weights, we have computed the coefficients of variation for individuals emerging from the same cup. Females are more variable in weight than males; the variation coefficients range from $16 \cdot 2$ to $18 \cdot 4$ in polymorphic, 
and 18.0 to 21.7 in monomorphic populations for females, from 15.0 to $17 \cdot 0$ in polymorphic and 16.7 to $19^{\cdot 1}$ in monomorphic populations for males. No consistent trend is shown by the variances of the mean weights; it may, or may not, be significant that in three of the four possible comparisons the monomorphic $\mathrm{CH}$ populations are the most variable ones.

TABLE 5

Mean weight (in mg.) of a fly, and variances of individual (intra-cup) and of mean (inter-cup) weights in polymorphic and monomorphic populations

\begin{tabular}{|c|c|c|c|c|}
\hline Population & Sex & Mean & $\begin{array}{l}\text { Variance of } \\
\text { individuals }\end{array}$ & $\begin{array}{l}\text { Variance } \\
\text { of means }\end{array}$ \\
\hline $173, \mathrm{AR}+\mathrm{CH}$ & Female & $0 \cdot 8485$ & о.о I 897 & 0.0107 \\
\hline $176, \mathrm{AR}+\mathrm{CH}$ & Female & 0.7963 & $0.0214^{8}$ & $0 \cdot 0094$ \\
\hline $175, \mathrm{AR}$ & Female & 0.8286 & 0.03312 & O.OIOI \\
\hline $177, \mathrm{CH}$ & Female & 0.8072 & 0.02415 & 0.0134 \\
\hline $\mathrm{I} 8 \mathrm{I}, \mathrm{AR}+\mathrm{CH}$ & Female & 0.8368 & 0.02151 & 0.0213 \\
\hline $\mathrm{I} 80, \mathrm{AR}$ & Female & $0 \cdot 9039$ & 0.02780 & 0.0173 \\
\hline $\mathrm{I} 82, \mathrm{CH}$ & Female & 0.8626 & 0.02399 & 0.0273 \\
\hline $\mathrm{I} 73, \mathrm{AR}+\mathrm{CH}$ & Male & 0.7371 & 0.01217 & 0.0069 \\
\hline $176, \mathrm{AR}+\mathrm{CH}$ & Male & 0.7018 & 0.01159 & 0.0043 \\
\hline 175, AR & Malc & 0.7047 & 0.01817 & $0 \cdot 0044$ \\
\hline $177, \mathrm{CH}$ & Male & 0.7031 & 0.01626 & 0.0103 \\
\hline $\mathrm{I} 8 \mathrm{I}, \mathrm{AR}+\mathrm{CH}$ & Male & $0.745^{6}$ & 0.01603 & 0.0178 \\
\hline $180, A R$ & Male & 0.7842 & 0.01799 & 0.0096 \\
\hline $182, \mathrm{CH}$ & Male & 0.7305 & 0.01483 & 0.0142 \\
\hline
\end{tabular}

\section{(iv) Biomass}

Multiplying the number of the flies hatching in the different cups by their mean weights, we obtain the total weights of the flies emerging in the different populations per unit of food (the nutrient medium in the cup). The figures so obtained are shown in table 6 . The results

TABLE 6

Total weights (biomass) in mg. produced per cup in different populations

\begin{tabular}{|c|c|c|c|c|c|c|c|}
\hline \multirow{2}{*}{ Sex } & \multicolumn{3}{|c|}{ Polymorphic populations } & \multicolumn{4}{|c|}{ Monomorphic populations } \\
\hline & No. 173 & No. ${ }_{176}$ & No. I8I & No. 175 & No. 177 & No. 180 & No. 182 \\
\hline q & $84 \cdot 82$ & $104 \cdot 71$ & I $57 \cdot 6$ I & $72 \cdot 17$ & $78 \cdot 15$ & $x \cdot 26 \cdot 32$ & 103.33 \\
\hline$\sigma^{\pi}$ & $5^{I} \cdot 80$ & $59 \cdot 87$ & $103 \cdot 5^{2}$ & $42 \cdot 86$ & $45 \cdot 7^{6}$ & $63 \cdot 88$ & $60 \cdot 23$ \\
\hline Total & $136 \cdot 62$ & $164 \cdot 5^{8}$ & $261 \cdot 13$ & $115 \cdot 03$ & $123.9^{I}$ & $190 \cdot 20$ & 163.56 \\
\hline
\end{tabular}

are clear and consistent if comparable populations are compared. Consider the Nos. I 73-I 77 series first. In the polymorphic populations, a cup produced from 85 to $105 \mathrm{mg}$. of females and from $5^{2}$ to $60 \mathrm{mg}$. of males, i.e. from $\mathrm{I} 37$ to $\mathrm{I} 65 \mathrm{mg}$. of flies. In the monomorphic populations a cup yielded from 72 to $78 \mathrm{mg}$. of females and from 43 to $46 \mathrm{mg}$. 
of males, i.e. from I I 5 to I $24 \mathrm{mg}$. of flies. In the Nos. I 80-I 82 series, the polymorphic population yielded ${ }_{5} 8 \mathrm{mg}$. of females and I $04 \mathrm{mg}$. of males, i.e. about $26 \mathrm{I} \mathrm{mg.} \mathrm{of} \mathrm{flies} \mathrm{per} \mathrm{cup.} \mathrm{The} \mathrm{comparable} \mathrm{mono-}$ morphic populations yielded I03 to I $26 \mathrm{mg}$. of females and 60 to $64 \mathrm{mg}$. of males, i.e. I64 to I $90 \mathrm{mg}$. of flies. The polymorphic populations are clearly more efficient producers of the living substance of the species Drosophila pseudoobscura.

\section{(v) Wing length}

The mean wing lengths characterising the different populations are shown in table 7 together with the variances attached to these

TABLE 7

Mean wing length (in mm.) and intra-cup (individual) variance and variance of means (inter-cup) in different populations studied

\begin{tabular}{|c|c|c|c|c|}
\hline Population & Sex & Mean & $\begin{array}{l}\text { Intra-cup } \\
\text { variance }\end{array}$ & $\begin{array}{l}\text { Inter-cup } \\
\text { variance }\end{array}$ \\
\hline $\begin{array}{l}\text { I } 73, \mathrm{AR}+\mathrm{CH} \\
\text { I } 76, \mathrm{AR}+\mathrm{CH} \\
\text { I } 75, \mathrm{AR} \\
\text { I } 77, \mathrm{CH} \\
\text { I } 81, \mathrm{AR}+\mathrm{CH} \\
\text { I } 80, \mathrm{AR} \\
\text { I } 82, \mathrm{CH} \\
\text { I } 73, \mathrm{AR}+\mathrm{CH} \\
\text { I } 76, \mathrm{AR}+\mathrm{CH} \\
\text { I 75, AR } \\
\text { I 77, CH } \\
\text { I81, AR }+\mathrm{CH} \\
\text { I80, AR } \\
\text { I82, CH }\end{array}$ & $\begin{array}{l}\text { Female } \\
\text { Female } \\
\text { Female } \\
\text { Female } \\
\text { Female } \\
\text { Female } \\
\text { Female } \\
\text { Male } \\
\text { Male } \\
\text { Male } \\
\text { Male } \\
\text { Male } \\
\text { Male } \\
\text { Male }\end{array}$ & $\begin{array}{l}2 \cdot 225 \\
2 \cdot 236 \\
2 \cdot 252 \\
2 \cdot 197 \\
2 \cdot 249 \\
2 \cdot 157 \\
2 \cdot 156 \\
2 \cdot 020 \\
2 \cdot 041 \\
2 \cdot 039 \\
2 \cdot 013 \\
2 \cdot 062 \\
2 \cdot 034 \\
1 \cdot 969\end{array}$ & 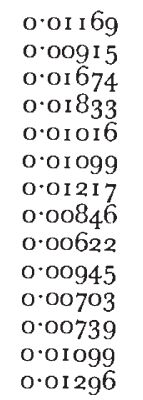 & $\begin{array}{l}0 \cdot 00268 \\
0 \cdot 00207 \\
0 \cdot 00452 \\
0 \cdot 00419 \\
0 \cdot 00126 \\
0 \cdot 00277 \\
0 \cdot 00335 \\
0 \cdot 00216 \\
0 \cdot 00153 \\
0 \cdot 00243 \\
0 \cdot 00212 \\
0 \cdot 00093 \\
0 \cdot 00377 \\
0 \cdot 00139\end{array}$ \\
\hline
\end{tabular}

values. In the I 70 series of populations it seems that the AR flies from population $\mathrm{I} 75$ have the longest wings and $\mathrm{CH}$ flies from population 177 have the shortest wings, the flies from the polymorphic populations being of intermediate wing length. In the i 80 series on the other hand, the mean wing length in the polymorphic population is greater than in both of the monomorphic populations. There is thus an indication that polymorphic populations may produce larger individuals than monomorphic populations but this is not inevitable and presumably depends largely upon external factors and upon the relative numbers of individuals produced in the two types of populations. It is to be expected that where more individuals are produced in a culture these will be smaller than when there are fewer. In fact the polymorphic populations produce more flies whose mean wing length is usually as great as, or greater than, those from monomorphic populations.

Comparison of the variances of wing length in the different populations gives, with a single exception, a quite consistent picture, namely that the polymorphic populations are less variable than the 
monomorphic ones. Let us consider the intra-cup (individual) variances first. In the 170 series of populations, the females in polymorphic populations show variances of $0.01 \mathrm{I} 7$ and 0.0092 , and in monomorphic ones 0.0167 and 0.0183 ; the males in polymorphic populations, $0 \cdot 0085$ and $0 \cdot 0062$, and monomorphic ones, $0 \cdot 0094$ and $0 \cdot 0070$ (the population No. 177 being exceptional). In the 180 series, the females in the polymorphic population have the variance of 0.0102 and in the monomorphic ones, 0.0110 and 0.0122 ; the males show 0.0074 in the polymorphic and 0.0110 and 0.0130 in the monomorphic ones. The variances of means (intra-cup) behave similarly. In the I 70 series, the females of the polymorphic populations give 0.0027 and $0.002 \mathrm{I}$, and of the monomorphic ones 0.0045 and 0.0042 ; the males in the polymorphic, 0.0015 and 0.0022 , and in the monomorphic ones, 0.0024 and $0.002 \mathrm{I}$ (the population No. $\mathrm{I} 77$ is again exceptional). In the 180 series, the polymorphic population gives 0.0013 and the monomorphic ones, 0.0028 and 0.0033 for females; and for males, 0.0009 in the polymorphic and 0.0038 and 0.0014 in the monomorphic populations.

The inescapable conclusion is that populations segregating for large genetic units are in general showing less phenotypic variation than populations pure breeding for these same units of inheritance.

\section{(vi) Asymmetry}

The mean intra-fly difference between right and left wings, i.e. wing asymmetry, calculated for each population is shown in table 8.

TABLE 8

Mean asymmetry of wings in microns in fies in different populations

\begin{tabular}{|c|c|c|c|c|c|c|c|}
\hline \multirow{2}{*}{ Sex } & \multicolumn{3}{|c|}{ Polymorphic populations } & \multicolumn{4}{|c|}{ Monomorphic populations } \\
\hline & No. 173 & No. 176 & No. I 8 I & No. 175 & No. 177 & No. 180 & No. 182 \\
\hline q & $8 \cdot 287$ & $8 \cdot 999$ & $8 \cdot 9 \circ 6$ & IO'I 74 & 10.548 & $10 \cdot 153$ & $8 \cdot 916$ \\
\hline o & $7 \cdot 9^{13} 3$ & $8 \cdot 459$ & 7.971 & $9 \cdot 83^{I}$ & $9 \cdot 659$ & $9 \cdot 259$ & $8 \cdot 54^{2}$ \\
\hline
\end{tabular}

It can readily be seen that, restricting comparisons to within the I 70 and 180 groups of populations respectively, flies from monomorphic populations are characterised by higher average values of wing asymmetry than flies from polymorphic populations. In fact, an analysis of variance shows that the apparent differences are statistically highly significant (table 9) in all except one of the informative comparisons $(181<182)$. In this connection it is worth noting that the flies from population 182 are here considerably shorter in wing length than those from I8I (see table 7 for mean wing lengths) and the asymmetry value is therefore correspondingly lower than it would have been had the mean wing length of flies from 182 been more 
nearly equal to that of the $18 \mathrm{I}$ flies. This is because the amount of asymmetry of bilaterally paired organs or structures appears to depend partly upon the absolute size of the organs themselves (Thoday, 1958). Thus, all other things being equal, flies with shorter wings have more symmetrical wings than flies with longer wings. In this case, population 182 flies have significantly shorter wings than population 181 flies but the same level of quantitative asymmetry; it seems reasonable to suppose that the homeostatic mechanisms of development are less efficient in the 182 flies than in 181 flies. This is, then, in general

TABLE 9

Comparisons of mean values of wing asymmetry in polymorphic and monomorphic populations

\begin{tabular}{|c|c|c|c|c|c|}
\hline \multicolumn{3}{|c|}{ Females } & \multicolumn{3}{|c|}{ Males } \\
\hline Polym. & Monom. & $\mathbf{P}$ & Polym. & Monom. & $\mathbf{P}$ \\
\hline $\begin{array}{l}\text { I } 73 \\
\text { I } 73\end{array}$ & $\begin{array}{l}<175 \\
<177\end{array}$ & $\begin{array}{l}<0.00 \text { I } \\
<0.00 \text { I }\end{array}$ & $\begin{array}{l}\text { I } 73 \\
\text { I } 73\end{array}$ & $\begin{array}{l}<175 \\
<177\end{array}$ & $\begin{array}{l}<0.001 \\
<0.001\end{array}$ \\
\hline $\begin{array}{l}\text { I } 76 \\
\text { I } 76\end{array}$ & $\begin{array}{l}<175 \\
<177\end{array}$ & $\begin{array}{l}<0.00 \text { I } \\
<0.001\end{array}$ & $\begin{array}{l}\text { I } 76 \\
\text { I } 76\end{array}$ & $\begin{array}{l}<175 \\
<177\end{array}$ & $\begin{array}{l}<0.001 \\
<0.001\end{array}$ \\
\hline $\begin{array}{l}\text { I 8I } \\
\text { I } 8 \text { I }\end{array}$ & $\begin{array}{l}<180 \\
<182\end{array}$ & $\begin{array}{l}<0.01 \\
<0.05\end{array}$ & $\begin{array}{l}\text { I } 8 \text { I } \\
\text { I } 8 \text { I }\end{array}$ & $\begin{array}{l}<\mathrm{I} 80 \\
<182\end{array}$ & $\begin{array}{l}<0.01 \\
<0.05\end{array}$ \\
\hline
\end{tabular}

agreement with the conclusion to be drawn from the other comparisons in table 9 , that is, that in the polymorphic populations develop ment is on average more homeostatic or better canalised than in the monomorphic populations.

\section{DISCUSSION}

Among the seven experimental populations which we have studied, four were monomorphic and three were polymorphic. Among the monomorphic ones, two were homozygous for third chromosomes with the AR gene arrangement and two homozygous for the $\mathrm{CH}$ arrangement. The polymorphic populations contained both $\mathrm{AR}$ and $\mathrm{CH}$ chromosomes, their frequencies approaching equilibrium values, i.e. AR being about twice as frequent as $\mathrm{CH}$. Among the zygotes formed in the polymorphic populations, slightly fewer than half were the heterokaryotype $\mathrm{AR} / \mathrm{CH}$, about one-third were the homozygotes $\mathrm{AR} / \mathrm{AR}$, and the remainder belonged to the homokaryotype $\mathrm{CH} / \mathrm{CH}$. Slightly more than half of the flies in the polymorphic population were, therefore, chromosomally identical with the flies in the monomorphic populations $\mathrm{AR} / \mathrm{AR}$ and $\mathrm{CH} / \mathrm{CH}$, respectively.

The findings described on the preceding pages must be interpreted in the light of the known composition of the experimental populations. We have found that the polymorphic populations differ in a number of 
respects from the monomorphic ones. The simplest explanation of this would seem to be that the properties of the polymorphic populations which distinguish them from the monomorphic ones are due to the presence in the former of the $\mathrm{AR} / \mathrm{CH}$ karyotype. The greater numbers of flies and the greater biomass produced in the polymorphic populations may, thus, be due to greatly superior survival rates of the $\mathrm{AR} / \mathrm{CH}$ class compared to the homozygotes. It is less easy to interpret similarly the lower variances found in the polymorphic populations, for this would mean that the AR/CH heterozygotes show a quite remarkably low variability. After all, the genetic component of the variance should be, if anything, greater in the polymorphic populations. Consideration should therefore be given to a possible alternative. Levene, Pavlovsky and Dobzhansky (1954, I958) found that the adaptive values of the karyotypes in experimental populations may be quite appreciably modified by the presence or absence of other karyotypes in the same medium. The fitness and other properties of, for example, AR/AR may, then, not be the same in a pure culture and in a culture in which $\mathrm{AR} / \mathrm{AR}$ shares the environment with $\mathrm{AR} / \mathrm{CH}$ and with $\mathrm{CH} / \mathrm{CH}$. There may quite conceivably exist a kind of mutual facilitation between the karyotypes which normally live side by side in natural populations. $\mathrm{AR} / \mathrm{AR}$ and $\mathrm{CH} / \mathrm{CH}$ may actually benefit by living in the vicinity of each other and of the AR/CH karyotype.

Regardless of whether the differences between the polymorphic and the monomorphic populations are due to a superiority of the heterozygotes or to mutual facilitation, it is important that these differences are of a kind which might be expected to confer a greater adaptedness on the former. The ability to produce a greater number of individuals and a greater biomass from a given amount of food would certainly be advantageous under most natural conditions. The lack of heterosis expressed in a greater weight or a greater size of the flies in the polymorphic populations is certainly compatible with the above view. In the first place, when a culture with a fixed amount of nutrients produces more flies these may well be smaller flies. Secondly, examination of fig. I suggests that there is a tendency for the flies from polymorphic populations to be heavier than flies from monomorphic ones when they develop in cultures with similar degrees of crowding (the triangle symbols in fig. I tend to be grouped above and to the right of the circles). And thirdly, it appears that flies from crowded cultures are as fecund as those from uncrowded ones if they are treated equally as adults (Spiess, I958, see, however, Saveliev, I928; this matter needs reinvestigation). Granted the unsatisfactory state of our understanding of Drosophila ecology, it would seem that a population which produces more flies is likely to have an advantage over one producing larger flies.

It is less easy to evaluate the adaptive significance of the lower variances of the productivity, of the weights of the individuals developing in the same cup, and of the lower degree of asymmetry of the 
wing length observed in the polymorphic populations. Dobzhansky and Wallace (I953), Dobzhansky, Pavlovsky, Spassky, and Spassky (I955), and Dobzhansky and Levene (1955) all found that the survival rates of heterozygous genotypes in Drosophila are less variable than those of the homozygotes. Furthermore, among the homozygotes, those less viable over a range of environments tend to be most variable (this is borne out also by unpublished data of Dobzhansky and Spassky). Interpretation of these findings has not been free from confusion; some writers alleged that other writers believed that the low variability of the survival rates caused these rates to be high. Perhaps the following comment may be helpful. Some genotypes endow their carriers with a superior developmental homeostasis, or, to use Waddington's (1957) terms, superior canalisation or superior homeorhesis, in a given range of environments. Other genotypes yield a less versatile developmental homeostasis. A superior homeostatic buffering should result in preservation of life and successful development, and consequently in a high viability, in a variable environment. But the same superior homeostatic capacity should make the survival rates over a certain range of environments more uniform, i.e. less variable. Uniformity of the survival rates is neither the cause nor the consequence of high viability; high survival and uniform survival are both conditioned by superior homeostasis (or canalisation, or homeorhesis).

Mather (1953) and Tebb and Thoday (1954) found that the numbers of sternopleural bristles on the two sides of the body in Drosophila melanogaster are more often asymmetrical in homozygotes than in heterozygotes. Although Thoday (I958) has shown that genetic imbalance rather than homozygosity as such is responsible for greater asymmetry in some cases, this agrees with our finding that the two wings of a fly are more often asymmetrical (different in length) in monomorphic than in polymorphic populations. Waddington (1957) ascribes asymmetries to "developmental noise", and draws a distinction between this phenomenon and the developmental instability resulting from imperfect homeostatic buffering. We feel that these phenomena are likely to be rather closely related; anyway, it is hardly an accident that heterozygous genotypes, at least those heterozygous for coadapted gene complexes derived from the same population, show both low variance in traits concerned with fitness and low asymmetry (see also Lerner, i954).

We conclude that experimental populations of Drosophila pseudoobscura polymorphic for $\mathrm{AR}$ and $\mathrm{CH}$ chromosomes are superior in fitness to populations monomorphic for AR or for $\mathrm{CH}$. This assuredly does not mean that monomorphic populations of this kind cannot be maintained; at least under laboratory conditions they are reasonably prosperous. But as Li (1955) has justly remarked: "Should man become a one-legged animal, we cannot be sure that mankind will perish from earth when raised in pure cultures", i.e. if all men should 
be one-legged animals. Polymorphic populations in Drosophila are superior to monomorphic ones in the same sense in which populations of two-legged men are superior to one-legged ones.

\section{SUMMARY}

Seven experimental populations of Drosophila pseudoobscura have been studied in laboratory population cages. Three of them were polymorphic for the $\mathrm{AR}$ and $\mathrm{CH}$ gene arrangements in the third chromosomes, two were monomorphic for AR, and two for $\mathrm{CH}$ chromosomes. The polymorphism is balanced owing to heterosis in the AR/CH heterozygotes. After the polymorphic populations had approached the equilibrium frequencies of $\mathrm{AR}$ and $\mathrm{CH}$, samples were taken from all the populations. The samples consisted of cups with the nutrient medium, withdrawn from the cages at a rate of, at most, one cup per week, during the period of mass pupation of the larvæ in the cups. The following data were obtained from the samples: (I) numbers of female and male flies hatching, (2) weights of individual flies, (3) length of the wings, (4) asymmetry of the lengths of the two wings of the same individual, and (5) total weight (biomass) of the flies hatching from a cup.

The results obtained show that $(a)$ the polymorphic populations produce more individuals than do the monomorphic ones ( $c f$. table 2), (b) the numbers of individuals hatching per cup are less variable in the polymorphic than in the monomorphic populations (table 2), (c) the mean weights of a fly are about the same in comparable polymorphic and monomorphic populations (tables $3-5),(d)$ the variances of weights of individuals hatching in the same cup are smaller in polymorphic than in monomorphic populations (tables 3-5), (e) the biomass produced is greater in polymorphic than in monomorphic populations (table 6), $(f)$ the mean length of the wings is about the same in polymorphic and monomorphic populations (table 7$),(g)$ the variance in wing length is generally greater in the monomorphic populations (table 7), (h) the asymmetry of the wings is greater in monomorphic than in polymorphic populations (tables 8 and 9 ).

We conclude that the polymorphic populations which we have studied are superior in Darwinian fitness to the monomorphic ones. It is conjectured that this superior fitness may be due not only to high adaptive value of the heterokaryotype $\mathrm{AR} / \mathrm{CH}$, but also to favourable interaction (mutual facilitation) between the carriers of the different karyotypes.

\section{REFERENCES}

dobzhansky, тh. 1948. Genetics of natural populations XVIII. Genetics, 33, $588-602$.

Dobzhansкy, тн. 1957. Mendelian populations as genetic systems. Cold Spring Harbor Symp. Quant. Biol., 22, 385-393.

Dobzhansky, TH., AND LEVENE, H. I955. Genetics of natural populations. XXIV. Genetics, $40,797-808$. 
DOBZHANSKY, TH., PAVlovsKy, O., SPASSKY, B., AND SPASSKY, N. 1955. Genetics of natural populations. XXIII. Genetics, $40,78 \mathrm{r}-796$.

DOBZHANSKy, TH., AND WALlaGe, B. 1953. The genetics of homeostasis in Drosophila. Proc. Nat. Acad. Sci., 39, г62-1 7 I.

Lerner, I. M. 1954. Genetic Homeostasis. John Wiley, New York.

LEVENE, H., PAVLOVSKY, O., AND DOBZHANSKY, TH. 1954. Interaction of the adaptive values in polymorphic experimental populations of Drosophila pseudoobscura. Evolution, 8, 335-349.

LeVene, H., Pavlovsky, O., DOBZhansky, Th. 1958. Dependence of the adaptive values of certain genotypes in Drosophila pseudoobscura on the composition of the gene pool. Evolution, I2, 18-23.

LEVINE, L. 1955. Genotypic background and heterosis in Drosophila pseudoobscura. Genetics, $4^{\circ}, 832-849$.

LI, c. C. 1955. The stability of an equilibrium and the average fitness of a population. Amer. Naturalist, 89, 28 I-295.

MATHER, K. 1953. Genetical control of stability in development. Heredity, 7, 297-336.

SAveliev, v. 1928. On the manifold effect of the gene vestigial in Drosophila melanogaster. Tr. Soc. Natur. Leningrad, 63, 65-88.

SPIESS, E. 1958. Chromosomal adaptive polymorphism in Drosophila persimilis. Evolution, I2, 234-245.

TEBB, G., AND THODAY, J. M. 1954. Stability in development and relational balance of X-chromosomes in Drosophila melanogaster. Nature, 174 , I rog.

THODAy, J. M. 1958. Homeostasis in a selection experiment. Heredity, I2, 40 I-4I5. WAdDington, G. H. 1957. The Strategy of the genes. Allen \& Unwin, London. 